\title{
Dois morros e seus moradores migrantes em Jaraguá do Sul-SC: "caxa" d'água e o pocinho, as "arvinhas" e um barraquinho de tábua velha, o esgoto e o mato
}

\section{Ancelmo Schörner}

Este texto é parte da pesquisa que realizamos para nossa tese de doutoramento em História, desenvolvida na Universidade Federal de Santa Catarina sob orintação da Professora Doutora Eunice Sueli Nodari e defendida em 2006. Ela foi feita em dois morros de Jaraguá do Sul no ano de 2003 sobre o seu processo de ocupaçáo, notadamente por migrantes paranaenses que chegaram à cidade a partir dos anos 1980 (entre 24/07/2003 e 21/08/2003 visitamos 65 casas no Morro da Boa Vista e falamos com 66 pessoas. No Morro da Pedra, as entrevistas foram realizadas entre 26/08/2003 e 05/10/2003, com 32 pessoas, sendo que algumas foram feitas por Cledir Weber, morador do Bairro Estrada Nova, onde se localiza o morro).

As entrevistas foram gravadas e transcritas pelo autor. Alguns entrevistados não concordaram com a gravaçấo e então fizemos anotaçôes sobre as respostas e voltamos a estes para que, após sua leitura, concordassem ou não com elas. Os entrevistados foram selecionados levando-se em conta o tempo de moradia em cada morro, ou seja, os moradores mais antigos foram entrevistados primeiro, uma vez que foram eles que nos contaram sobre a formação

1 Doutor em História. Pós-doutor pelo Programa de Estudos Pós-Graduados em Ciências Sociais da PUC/SP. Professor do Departamento de História da Unicentro/PR - campus de Irati. Programa de Pós-Graduação em História - UNICENTRO - PR 
do morro, como foram as lutas por água e demais equipamentos urbanos. Ao longo de nossas idas aos morros, outros moradores foram incorporados ao processo. Os roteiros foram elaborados em conjunto com a orientadora e pensados a partir das questóes que nos interessavam, como, por exemplo: como foram morar no morro; em que época foram para lá; como se deu o processo migratório; quais as principais dificuldades de morar no morro; como conseguiram comprar os terrenos e construir suas casas; como conseguiram os primeiros empregos. As entrevistas estão gravadas e disponíveis para outros pesquisadores. Cledir Weber realizou algumas entrevistas, tendo como base o roteiro por nós elaborado, por ser morador do Bairro Estrada Nova e conhecer muitos moradores do Morro da Pedra, com os quais fomos conversar depois de apresentados. Além disso, isso se deu em um momento em que nos encontrávamos fazendo outros trabalhos de leituras de fontes, como as disponibilizadas pela Prefeitura sobre os loteamentos em Jaraguá do Sul.

Um dos morros, o da Boa Vista, é um dos espaços mais antigos de ocupação, remetendo-nos ao início do processo de colonização, a partir da década de 1870. Neste morro, seus moradores, originalmente negros vindos do Rio de Janeiro e do Nordeste para trabalhar no Engenho Jaraguá, de Emílio Carlos Jourdan, o criador da Colônia Jaraguá, convivem com o abandono, o descaso e a segregaçáo. O outro, o da Pedra, expressa de maneira clara as tensôes existentes entre "nós" e os "outros", haja vista que seus moradores sofreram, e ainda sofrem, processos de culpabilização e criminalização. Sua ocupaçáo é mais recente e remonta aos anos de 1980.

A explicação geográfica, ao naturalizar este processo, omite justamente os ingredientes históricos e geopolíticos dessas construçóes. Assim, a periferia reuniria habitantes de áreas longínquas, dentro de uma perspectiva de distância definida náo exatamente pela extensão medida em metros, uma vez que pode se situar, muitas vezes, dentro ou próxima às áreas centrais: a periferia não é somente espacial, mas econômica, social (Gomes, 2002, p. 193). A distância é, sobretudo, uma imagem que considera o sentido dessas áreas como periféricas ou marginais aos limites da cidade, esta última sendo tomada como um espaço onde predomina uma determinada sociabilidade que exclui essas áreas. Periferia é tudo aquilo que está fora do centro, mas não necessariamente longe.

Estes morros são paradigmáticos de um processo de urbanização que envolve, ao mesmo tempo, migraçáo, impactos ambientais, abandono do 
poder público, falta de equipamentos urbanos mínimos. Além disso, neles predomina, hoje com menor intensidade, o que se convencionou chamar de autoconstrução, processo de construção de moradias pela população de baixa renda. Observamos que não há dados precisos sobre quando construíram suas casas nessas condiçóes, mas quase tosos os moradores entrevistados citaram essa condição como sendo a única possível para que pudessem construir suas casas. Assim,

(...) autoconstrução é o processo de construção da casa (própria ou não) seja apenas pelos seus moradores, seja pelos moradores auxiliados por parentes, amigos e vizinhos, seja ainda pelos moradores auxiliados por algum profissional (pedreiro, encanador, eletricista) remunerado (Maricato, 1982, p. 73-74).

Se morar é uma necessidade para todos, é na desigualdade da localização e da qualidade habitacional desfrutada que transparecem as diferenças entre as classes sociais, fazendo-se o urbano como expressão de conflitos sociais. Submetida à lógica do capital, que acumula a população exigida para o sistema produtivo e o exército de reserva que pressiona os salários para baixo e é volante de máo-de-obra, a cidade se apresenta com efeitos visíveis, decorrentes da valorização da mercadoria do solo urbano: congestionamento; verticalização dos centros melhor servidos de infraestrutura e equipamentos; proliferação de zonas segregadas; subúrbios mal equipados e periféricos, como cinturão de abordagem aos mais pobres; casas precárias alugadas; casas por "autoconstruçáo" e assim por diante, todos expedientes de que se serve o trabalhador pauperizado para solucionar seu problema de moradia (Véras, 1992, p. 85-86).

A casa própria, produto da auto-construção na periferia das cidades brasileiras, já fazia parte da paisagem desde o final dos anos 1940, fixando as camadas populares, muitas vezes, em loteamentos clandestinos ou irregulares. É uma cidade clandestina, tanto quanto à propriedade efetiva da terra, como quanto às normas dos códigos de edificaçóes. A periferia, assim, é uma concessão necessária à falta de direitos à cidade (Damiani, 2001, p. 56).

Para Siebert (2000, p. 291, grifo no original), distinguem-se, por sua presença no espaço urbano, as invasóes (áreas nas quais a ocupação não se dá por iniciativa de seu proprietário), os loteamentos clandestinos (quando o proprietário vende os lotes sem conhecimento da prefeitura, sem projeto 
nem infraestrutura) e os loteamentos irregulares (quando o proprietário vende os lotes sem aprovação final da prefeitura, sem infraestrutura completa, mas com um projeto encaminhado para aprovação). Na prática, estas três categorias de ocupação ilegal geram os mesmos problemas básicos: falta de um registro oficial da propriedade (legitimação), falta de infraestrutura e falta de segurança - em suma, falta do que se espera de uma cidade e que deveria estar implícito na cidadania.

A migração massiva fornece força de trabalho abundante para o crescimento industrial, porém as péssimas condiçôes de moradia na cidade que acompanha essa população migrante, não se devem apenas à velocidade e à intensidade da migração. Nas formas de produção do espaço urbano, está outra fonte que explica a carência, a segregação ou as más condiçóes de moradia. A demanda por moradias e correspondentes serviços e equipamentos urbanos é muito grande, mas nada é feito de significativo, em termos de política pública, para seu atendimento. Ao contrário, ao favorecer os interesses do capital imobiliário e das grandes empreiteiras, as políticas governamentais fortaleceram, mais do que combateram, a segregação espacial.

É preciso constatar, portanto, que a moradia vai além do terreno, pois terra urbana significa terra servida por infraestrutura e serviços (rede de água, rede de esgotos, rede de drenagem, transporte, coleta de lixo, iluminação pública, além dos equipamentos de educação e saúde). A produção da moradia exige um pedaço de cidade e não de terra nua. Há a necessidade de investimentos sobre a terra para que ela ofereça condiçóes viáveis de moradia em situação de grande aglomeração. Como esses investimentos conferem rendas aos proprietários fundiários e imobiliários, a disputa pelas localizaçóes e por investimentos públicos nas cidades é crucial (Maricato, 2001, p. 119).

Como os custos da moradia estão cada vez mais caros, a solução de sobrevivência mais econômica, mas também mais dramática, são os morros, a periferia, para onde são drenados os patamares mais pobres da classe trabalhadora. A autoconstrução passa a ser vista como a solução mais importante do ponto de vista quantitativo, haja vista que as moradias são construídas em processo de mutirão, através da ajuda mútua, nos dias de folga, nos finais de semana, ao fim do dia de trabalho. Os mutiróes, contudo, não se limitam à construção das casas. No Morro da Boa Vista, por exemplo, o mutirão foi utilizado para a construção de uma igreja e do centro comunitário. 
O processo de ocupação dos morros pelos pobres, migrantes, através da autoconstrução, sem critérios técnicos, com remoção da cobertura vegetal, com cortes e aterros náo estabilizados e sem obras de drenagem, aumenta os riscos de deslizamento, consolidando o círculo vicioso da exclusão econômica, da exclusão espacial e da exclusão social (Siebert, 2000, p. 292), produzindo e reproduzindo uma forma de expansão urbana extremamente dilapidadora para aqueles que não têm recursos econômicos e políticos para pagar o preço de um progresso altamente espoliativo (Kowarick, 2000, p. 28).

A autoconstrução e o mutirão são termos usados para designar um processo de trabalho calcado na cooperação entre as pessoas, na troca de favores, nos compromissos familiares, diferenciando-se, portanto, das relaçóes capitalistas de compra e venda da força de trabalho. Através do mutirão, firma-se um compromisso de troca de favores, em bases bastante espontâneas, apesar de ser ditado pela necessidade.

Entre os migrantes moradores do Morro da Boa Vista e do Morro da Pedra, esse mecanismo foi (e ainda é, em menor escala) acionado várias vezes, de modo a se fundir lajes ou fundamentos, construir casas, levantar muros. É principalmente através da autoconstrução que a maioria da população trabalhadora resolve o problema da habitação, trabalhando nos fins de semana, ou nas horas de folga, contando com a ajuda de amigos ou parentes, ou apenas com a própria força de trabalho (marido, mulher e filhos), como podemos observar nos depoimentos que seguem.

Morava muita gente, muitas famílias em uma só casa nos primeiros dias. Depois a gente ia arrumando uns puxados prá eles e ia se resolvendo. Aqui mesmo no meu terreno chegou a morar três famílias de uma só vez. Depois construímos um barraco pra um, puxamos outra parte pra outro e hoje eles têm suas casas. Não é lá grande coisa, mas é deles, não pagam aluguel nem nada. A gente ia construindo tudo no final de semana, quando dava. Uns ajudavam os outros e depois se ia pra outra casa e até que todos os que vinham da terra da gente não tinham seu lugar prá morar não se parava de construir. Aqui no Morro da Pedra foi assim com quase todo mundo. Se não fosse assim ficava difícil (Marcelino, Morro da Pedra).

Aqui tinha emprego mesmo. Só era difícil de arrumar lugar pra morar. Aí a gente veio aqui pro morro com a família e construiu um ranchinho. É aquele ali em cima, branco, que ainda tá de pé. Ele foi nossa primeira casa. Depois 
ia construindo outra casa e outra e todos os filhos se ajudando e tudo se encaminhou que todos têm casa hoje. Tinha o Júlio que é pedreiro que era quem fazia as casas, mas todos ajudavam. Tudo a gente puxava lá de cima, da rua. Era um sofrimento só. [...]. Não tinha estrada, era só mato. Ninguém ajudou, nem a Prefeitura. Até pra fazer um pocinho foi sofrido. Construímos tudo na força, capinando, abrindo esgoto, fazendo casa. A nossa, dá prá vê, tá há treze anos em construção (Dona Maria Clara, Morro da Boa Vista).

Além disso, a existência de mais de uma casa no mesmo terreno é frequente. A do fundo, normalmente a mais velha e precária, se prolonga e melhora para frente, ou vice-versa. Nestas residências múltiplas, os cômodos são alugados ou cedidos a parentes e conhecidos. Mas também vão se construindo mais casas para parentes, amigos e conhecidos. A maioria das casas no morro são limpas, mas em precárias condições de conservação, sendo que algumas não apresentam nenhuma condição de moradia. Amontoadas em pequenos terrenos, estáo, às vezes, quatro ou cinco casas, onde moram seis ou sete famílias, como é o caso "lá de baixo, perto do seu Argeu que tem umas cinco casas construídas num terreno. É tudo junto, amuntuado. Deve de ter umas sete famílias morando lá” (Maria Rosa, Morro da Boa Vista).

Para Jacobi, por casas coletivas entende-se

as moradias coabitadas por várias famílias em casaróes, porôes ou cômodos de quintal e estão geralmente localizadas em loteamentos situados em bairros periféricos com condiçôes precárias de urbanização. Têm como características a superlotação dos cômodos, com grandes deficiências de ventilação e iluminação, insuficiência de recursos hidráulicos, que geram saturação e precariedade no uso de banheiros e pias. Isto confirma uma degradação de condiçóes de habitabilidade, marcada por problemas de infiltrações e vazamentos (Jacobi, 200, p. 13).

Durante nossa pesquisa, 93,8\% (61 moradores) disseram que há coleta de lixo. Acontece, contudo, que em muitos pontos do morro o caminhão não chega e os moradores náo o levam até os outros pontos de coleta, acabando por jogá-lo na rua, no riacho ou por queimá-lo (prática que já causou vários incêndios nas suas matas e encostas), deixando espaço para a identificaçáo automática entre a sujeira e os moradores do morro, notadamente os negros do Morro da Boa Vista. 
Para Jacobi (2000, p. 11), o meio ambiente pode ser analisado a partir do entorno e do domicílio, das condiçóes de moradia e do poder aquisitivo, das condiçôes de habitabilidade, das instalações sanitárias e de higiene, da identificação dos problemas domiciliares referentes às condições de abastecimento de água e de seu armazenamento, da disposição de resíduos sólidos, da presença de insetos e de roedores. Assim, a distribuição incompleta de água, os sistemas de esgoto quase inexistentes, a coleta inadequada do lixo, a construção em morros muito inclinados e sujeitos à erosão e em várzeas sujeitas a enchentes, as casas mal-construídas, mal-ventiladas e mal-iluminadas combinam para produzir o ônus ambiental da vida diária na periferia.

Segundo Caiado (1997, p. 119), o entorno da residência é adequado quando a rua possui algum tipo de pavimentação, guia de sarjeta e iluminação pública, e transporte coletivo passando a uma distância de até 500 metros da moradia. O que sair disso é inadequado. Quanto à oferta de equipamentos sociais, a existência de escola de primeiro grau, de posto de saúde e de praça ou área de lazer torna a habitação adequada. Caso não exista um ou mais deles, é considerado inadequado.

Água o povo pega na nascente do morro, que nós se criamos assim, com água do morro. Tem da SAMAE em algumas casas, mas a gente daqui de cima pega sempre do morro. Isso já faz quase cem anos que é assim, que os antigos já bebiam água do morro. É tudo água sem tratamento, mas às vezes tem água com cloro que acaba sobrando da caxa da SAMAE lá mais pra cima. Aí tem algum tratamento. Como ela chega até nas casas? A gente bota uma mangueira na fonte e uma caxa d'água logo embaixo, depois mais pra baixo coloca outra caixa com uma tela em cima que é pra não entrar sujeira, bicho, essas coisas. De lá ela vem até nas casas. É uma água boa, boa mesmo. Já tomo dela há 47 anos e nunca me deu nada. (Maria Bernardete Rosa, Morro da Boa Vista).

\section{"Batendo martelo": a autoconstrução como cenário do "novo em ruínas"}

Não são poucos os casos em que a construção dessas moradias se estende por anos, pois os proprietários só podem trabalhar nelas nos seus dias de des- 
canso semanal. Diferentemente dos bairros de renda alta, seus pequenos lotes são totalmente ocupados por construçóes geminadas, de acabamento e cuidado estéticos precários e sem áreas verdes (Scarlato; Pontin, 1999, p. 63-64).

A autoconstrução apresenta-se como um cenário do "novo em ruínas", pois a casa começa a deteriorar-se antes de receber o material de acabamento (não estamos nos referindo ao supérfluo, evidentemente), dado o largo tempo de uso que precede a este.

Aqui eu fui morar de aluguel na casa de um colega conhecido lá do Paraná. Passado um tempinho foi comprado em quatro um terreno no morro e construída uma casa. Aí meus irmãos foram saindo, casando, voltando pro Paraná e eu fiquei com o terreno. Foi o meu irmão que era pedreiro que construiu a casa. Era uma casa de madeira. Hoje já tem uns tijolos, mas ainda não está pronta e nem bem se acaba uma parte a outra já tá velha (Edenilson, Morro da Pedra).

As formas de construção da moradia variam, mas na maior parte dos casos, o encargo recai sobre a família autoconstrutora, de modo que poucos entrevistados declararam ter usado mão-de-obra remunerada. Isso ocorre porque são poucos os que têm recursos para planejar o andamento da obra de modo a assalariar trabalhadores de maneira regular. Produzida por técnicas rudimentares, a casa serve como abrigo, uma vez que sua finalidade é gerar um componente indispensável para subsistir nas cidades e não obter lucro por sua venda. É preciso enfatizar que esse tipo de produção de moradia supóe, de um lado, um tempo de trabalho suplementar no processo produtivo, que se traduz na ampliação da já normalmente extensa jornada de trabalho, venda de férias, "bicos" e outros expedientes que os trabalhadores precisam desenvolver para levar adiante a realização de sua casa própria. (Kowarick, 2000, p. 29).

A autoconstrução produz-se por trabalho não pago e contribui para aumentar a taxa de exploração da força de trabalho, pois seu resultado, a casa, reflete-se numa baixa aparente do custo de reprodução da força de trabalho de que os gastos com habitação são um componente importante. Assim, uma operação que é, na aparência, uma sobrevivência de práticas de "economia natural" dentro das cidades, casa-se admiravelmente bem com um processo de expansão capitalista que tem uma de suas bases e seu dinamismo na intensa exploração da força de trabalho (Maricato, 1982, p. 74). 
Aqui no morro onde a gente foi morar o terreno não tinha nenhum tipo de legalização. Era parte das terras da família Rosa e ninguém se preocupava em legalizar as coisas, a construçáo da casa. Tudo era feito meio no escuro, meio que invadido. (...). A nossa primeira casa meu pai mesmo construiu e demorou uns dois anos pra ficar pronta porque ele fazia no final de semana. A nossa casa hoje está sendo feita do mesmo jeito e acho que vai demorar um bom tempo prá ficar pronta (Madalena, Morro da Boa Vista).

Logo depois que eu cheguei, há 14 anos, comprei o terreno, comecei a fazer a casa na base do mutirão nos finais de semana com a ajuda do meu irmão. Toda semana se fazia um pouco porque o material era caro e a gente não tinha tempo, tinha que trabalhar, e pagar pedreiro não dava (José da Rosa, Morro da Pedra).

A ingênua busca da criação arquitetônica popular resulta bastante frustrada, dada a articulação rígida de todos os elementos que se compóem na determinação do produto, a casa popular: o lote, de dimensôes pequenas; os materiais baratos, simples, de manipulação fácil e largamente conhecidos; a mão de obra náo especializada e intermitente; a técnica rudimentar; poucas ferramentas, nenhuma máquina e a disponibilidade parcelada de tempo e dinheiro, o que determina a construção por etapas (Maricato, 1982, p. 91). A diferença entre licenças para edificação e "habite-se" concedidos em Jaraguá do Sul entre 1997 e 2000 refletem isso. No total, foram concedidas 4.915 licenças e apenas 1.887 "habite-se" (Prefeitura de Jaraguá do Sul, 2001, p. 12).

No Morro da Boa Vista, o padrão de construção é mais precário do que no Morro da Pedra, com espaços mal iluminados, pouco ventilados e bastante adensados. $\mathrm{O}$ acesso à infraestrutura urbana é muito restrito, e as instalaçóes sanitárias são precárias, assim como as condiçóes de habitabilidade. A falta de espaço, aliada ao inacabado da construçáo, acabam dando às casas o aspecto de "bagunça" pela qual os moradores náo cansam de se desculpar para qualquer visita. Mas quem olhar mais atentamente para a organização de uma dessas casas, vai poder perceber que, ao contrário da bagunça, o que impera é um grande sentido de ordem e, apesar das condiçóes adversas que poderiam dar a impressão imediata de sujeira, o que existe é um zelo muito grande no cuidado da casa e de sua higiene - se não fosse por mais nada, em geral as mulheres gastam boa parte do seu tempo limpando e arrumando a 
casa. Dentro dela, cada coisa tem o seu lugar e, nos menores detalhes, pode-se perceber a tentativa de tornar o espaço agradável (Caldeira, 1984, p. 110).

Em muitos casos, a construção de um barraco é para ser uma situação provisória, pois este apresenta uma série de desvantagens em relação à casa de alvenaria: menor durabilidade, problemas de infiltração de água, proliferação de insetos e ratos, desconforto ambiental, falta de segurança. Contudo, em função dos problemas econômicos da maioria dos moradores, eles não são terminados nem abandonados. A sua existência é o sinal evidente de condiçóes de habitação precárias: ausência de revestimentos mínimos (mata-junta e rodapé), banheiro para fora, rabichos de água e luz, mais de uma família morando.

A saída pra quem chegava sem condiçóes, que era a maioria, era morar na casa de um conhecido, de um parente, ou alugar uma peça até que se ajeitavam as coisas. Eu morei seis meses de casa alugada e quando vendi o terreno que tinha no Sul comprei esse aqui no morro, que era mais barato. Em cima do lote tinha uma casa, que já estava pronta, mas que precisava de umas melhoras. Com o tempo eu mesmo fui ajeitando uma porta aqui, uma janela ali, botando forro. Ainda hoje faltam umas coisinhas, que um amigo meu me ajuda reformar. Inclusive ela está na casa agora trabalhando (Vilmar, Morro da Boa Vista).

Moramos uns tempos de aluguel e depois meu irmáo comprou um terreninho em prestaçóes, que demoramos quase nove anos prá pagar. Uma casa já tinha em cima dele, mais era velha e foi sendo reformada, mas até hoje não se acabou de construir, porque sempre tem coisa pra fazer (Margarida, Morro da Boa Vista).

As casas abaixo da estrada são as que apresentam as maiores dificuldades para serem construídas, haja vista a distância de onde ficam os materiais, as betoneiras (quando existem). $\mathrm{O}$ material é deixado na beira da estrada e deve ser levado nas costas barranco abaixo pelas escadas encravadas na terra. Em uma casa isso significou 84 degraus abaixo da rua principal. Quando não há energia elétrica, o concreto para as vigas ou fundamento, a massa para assentar tijolos é feita à mão, em caixas de madeira. No caso das casas de madeira, as dificuldades não são diferentes: tudo deve ser carregado da estrada até o local da construção, o que na maior parte das vezes é feito clandestinamente, pois não há registros dos terrenos e/ou alvarás de construção. 
Muitas vezes, as casas são erguidas em locais proibidos e deve-se escapar dos fiscais da Prefeitura, "fazendo tudo rápido, pois daí com a casa pronta não tem como eles tirar a gente daqui" (V. B., Morro da Boa Vista).

Quando cheguei aqui fiquei morando com uns conhecidos um mês aqui no morro e depois comprei esse terreninho e construí a casa. Isso foi o maior sacrifício que nós passemos aqui. É que a casa, como se vê, fica aqui embaixo no morro e o material ficava lá em cima e tinha que puxar tudo no braço aqui prá baixo. Quando chegava a hora de parar prá almoçá ou descansar era todo mundo tremendo de tanto fazer força, de subir e descer esse barranco. (...) a gente morou primeiro num ranchinho de madeira e depois foi construindo a casa aos pouco, no fim de semana, feriado, hora de folga. Quando dava a gente batia martelo aqui na casa. (...). Ela está sendo construída fazem 12 anos (Alvir, Morro da Boa Vista).

A propriedade, mesmo ilusória, do terreno e o imenso esforço para a construção da casa constituem penosos investimentos em longo prazo - a população fixa-se, assim, de modo relativamente permanente no local, presa a um projeto interminável. Por outro lado, como tende a ser semelhante o nível de rendimentos dos que compram os terrenos, cria-se uma uniformidade relativa da população, segregada pela distância e pela dificuldade do transporte para o resto da cidade (Durham, 1986, p. 86).

Casas ou barracos provisórios são erguidos em algum terreno do Morro da Boa Vista, onde o lote, no mais das vezes, é clandestino do ponto de vista da legislação urbanística, mas é "próprio" do ponto de vista dos moradores. Essas condições de moradia, em que pesem todos os problemas, permitem arranjos mais adequados para enfrentar a dinâmica espoliativa e pauperizada da cidade. Parece plausível supor que a situação de vida daqueles que moram nos morros dificilmente será um atributo neutro na confecção das assim chamadas concepçôes de mundo. Sem dúvida, os reflexos sociais e políticos dessa condição discriminatória de moradia irão depender dos embates e debates que cortarão os diversos cenários e atores da cidade de Jaraguá do Sul.

Assim, sem ajuda oficial e com dificuldade para conseguir empréstimos, os trabalhadores terminam construindo suas casas através da autoconstrução, processo em longo prazo pelo qual os trabalhadores compram um lote, constroem um quarto ou um barraco nos fundos deste, onde passam a morar, e então gastam anos expandindo e melhorando a construção, mobiliando e decorando a casa. 
Aqui as casa foram construídas dentro do alcance de cada um, com a ajuda dos outros nos finais de semana, nos tempo de folga. Um ajudava o outro e assim se ergueram todas essas casas que se pode ver daqui. [...]. Tudo com muita dificuldade e sofrimento, que ninguém podia se mostrar muito que a Prefeitura vinha e mandava embora (S. P., Morro da Boa Vista).

O terreno que eu moro é cedido pela família Rosa, de quem sou parente. É parte de uma herança. Há uns tempos atrás tinha uma moradia velha, de madeira no chão, mas agora já erguemos uma de tijolo. (...). Quem fez ela foi o meu marido, que é pedreiro. Demorou seis anos pra ficar pronta, que a gente ia fazendo aos pouquinhos, com a ajuda de amigos (Maria Rosa, Morro da Boa Vista).

Como as possibilidades de compra ou do aluguel da casa estão diretamente relacionadas às condiçóes de pagamento que, por sua vez, são função dos padróes de renda e do papel que cada um desempenha no sistema, a cidade erige-se pela diferenciação e separação das classes. $\mathrm{O}$ desenho urbano é um denunciador representativo desta segregação do espaço, e a segregação residencial é uma expressão espacial das classes sociais que se verifica basicamente devido ao diferencial da capacidade que cada grupo social tem de pagar pela residência que ocupa, a qual apresenta características diferentes no que se refere ao tipo e à localização.

Na determinação do preço dos lotes, o mais importante é a fixação de uma prestação compatível com a disponibilidade de pagamento do trabalhador de baixa renda, cujo cálculo já leva em conta que este fará sacrifícios para pagar o lote, considerando a importância que atribui à casa própria. $\mathrm{O}$ morador não está prioritariamente preocupado com o preço total do lote nem com o número de prestaçóes, mas sim com o quanto irá despender por mês. Assim, o loteador fixa a prestação como uma porcentagem do salário mínimo e, na medida em que o preço total do lote é estabelecido no ato de venda e não sofre reajustes, o período de pagamento das prestaçóes não é prefixado, situando-se, em geral, entre cinco e dez anos. Quanto ao valor da entrada, não há regra geral, dependendo principalmente do investimento aplicado pelo loteador.

Desta forma, o preço do lote, quando ele é comprado, varia conforme a localização da residência, a produção social incorporada à moradia, bem como em função das facilidades de circulação e de toda a infraestrutura, elementos de valorização do espaço e do solo urbano. 
Os terrenos aqui se compravam em prestaçóes da própria dona, a Marina, e isso dependia de como estava o bolso do comprador. Náo tinha uma regra fixa. A casa náo tinha e a gente mesmo ia fazendo aos poucos ou pagando, quando dava, pro pedreiro erguer, arrumar ou ir acabando aos pouquinhos. A minha mesmo ainda não está pronta até hoje e isso já vai pra quase 11 anos (Veroni, Morro da Pedra).

Segundo muitos moradores do Morro da Boa Vista, as relaçóes de compra e venda de terrenos se davam levando-se em conta com quem se estava negociando. Disso dependia o valor total, as condiçóes de pagamento, o valor da entrada. Em sua maioria, os terrenos eram comprados de conhecidos muito próximos, de parentes. Em outros casos, muitos deles eram simplesmente ocupados - por isso no Morro da Boa Vista os moradores não têm endereço, as casas não têm número -, como no caso dos depoimentos que seguem.

Quando cheguei no morro não tinha onde morar e uma pessoa da Prefeitura de Jaraguá disse que eu podia construir uma casa no morro, desde que cuidasse para que outros não viessem, desmatassem e construíssem casas. Mas isso não deu certo, náo por culpa minha, porque aqui tem um monte de gente nessa situaçáo (S. P., Morro da Boa Vista).

O terreno que eu moro era do sogro, não tem contrato nem nada. A casa ainda tá em construção. Eu não tenho energia própria, pego extensão do vizinho, água pego do morro mesmo. Construí minha casa sem licença, sem nada. Um dia quando eu tava construindo veio um fiscal da prefeitura e parou na frente da casa, que estava sendo erguida nos fundos do terreno, em um lugar desmatado pra isso. $\mathrm{O}$ fiscal não se aproximou da obra (risos) por causa de um cachorro grande que eu tinha. Ele perguntou se o cachorro era brabo e eu disse que sim e ele foi embora, acho que ficou com medo. Mas era mentira, o cachorro não dava conta com as pernas (risos). Eu levantei ela e ninguém apareceu (V. B., Morro da Boa Vista).

No Morro da Pedra a situação é outra, haja vista que, inicialmente, todos os terrenos foram comprados, primeiro do esposo de Dona Marina, e depois dela própria. Contudo, as formas e condiçóes de pagamento dependiam mais das condiçóes do comprador do que de uma regra estipulada por eles. Assim, podemos encontrar pessoas que compraram o terreno "dando 
a casa que tínhamos lá no Paraná como entrada e o resto foi se negociando com a Dona Marina mesmo" (Cleonice é de Coronel Vivida (PR). Mora no Morro da Pedra desde 1991).

Porém, é comum, nos dois morros, o comprador, ao perceber que não consegue quitar as prestaçóes atrasadas, revender o lote, sintoma de uma problemática bem mais ampla: a segregação do território urbano (Bonduki; Rolnik, 1982, p. 142). Esta situação leva os trabalhadores a migrarem novamente para outros loteamentos, geralmente áreas mais precárias, caracterizando uma "marcha da propriedade", processo que pode durar vários anos e comportar várias etapas de mobilidade residencial (Venetier, 1989, p. 266).

$\mathrm{Na}$ autoconstrução, o trabalho realizado torna-se um sobre-trabalho, pois é totalmente gratuito e realizado nas horas que deveriam ser destinadas ao descanso e ao lazer. Representa, além de desgaste físico, também gastos adicionais com transportes, comida e ferramentas para se fazer aquilo que, na verdade, é obrigação do Estado, porque morar é um direito social que deve ser garantido a todo cidadão. Assim, a autoconstrução é uma magnífica fórmula que o capitalismo deflagrou para rebaixar o custo de reproduçáo da força de trabalho, compatibilizando uma alta taxa de acumulação com salários deteriorados (Kowarick, 1993, p. 64).

Embora esse bem não seja desapropriado pelo setor privado da produçáo, ele contribui para aumentar a taxa de exploração da força de trabalho - pois o seu resultado, a casa, reflete-se numa baixa aparente do custo de reproduçáo da força de trabalho, de que os gastos com habitação são um componente importante - e para deprimir os salários reais pagos pelas empresas. Assim, uma operação que é, na aparência, uma sobrevivência de práticas de "economia natural" dentro das cidades, casa-se admiravelmente bem com um processo de expansão capitalista, que tem uma de suas bases e seu dinamismo na intensa exploração da força de trabalho (Kowarick, 1993, p. 64).

Poder-se-ia argumentar que, com o passar do tempo, a casa pode ser melhorada. Isto pode ocorrer, mas a um custo excessivamente alto. A compra em pequena quantidade normalmente encarece o custo da construção. Depois, vale lembrar que nos pequenos depósitos da periferia, via de regra, os materiais são mais caros. Praticamente não existem linhas especiais de financiamento, e quando se vende a prazo, o comerciante cobra juros exorbitantes como forma de se precaver contra uma possível inadimplência. Isto tudo 
leva a que se opte sempre pelos materiais mais baratos e, consequentemente, de pior qualidade. Os constrangimentos de ordem financeira e de tempo disponível fazem com que, mesmo depois de já habitada a casa, o processo de ampliação e melhoria arraste-se por anos, consumindo recursos valiosos e o tempo de lazer. Na maioria das vezes, em função do material utilizado, de falhas técnicas e do longo período de construção, a deterioraçáo se inicia antes mesmo que o projeto final da casa se encontre terminado.

$\mathrm{Na}$ ausência de alternativa habitacional regular, a população apela para seus próprios recursos e produz a moradia como pode. As consequências desse universo de construção, completamente desregulado, ignorado pelo Estado, são trágicas, dadas suas dimensóes (Maricato, 2001, p. 44). As casas são construídas em mutirão, muitas vezes, ou pelos próprios moradores nos finais de semana; muitos deles são "pedreiros" e isso facilita a construção, como é o caso de Seu Armando, do Morro da Boa Vista, quando nos dizia que "(...) aqui tinha uma casinha velha em cima do terreno, que depois eu mesmo derrubei e fiz outra, que nesse tempo eu já sabia trabalhar de pedreiro" (Seu Armando, Morro da Boa Vista).

As dificuldades são enormes e as casas vão sendo construídas ao longo de vários e intermináveis anos. No Morro da Boa Vista, por exemplo, várias delas estão em obra há mais de dez anos, pois "sempre se tem uma coisinha prá fazer" (Paulo, Morro da Boa Vista), o que vai contribuindo para o adiamento do sonho de terminar a casa.

\section{Precariedade habitacional: usando o mesmo fogão e morando empilhado}

Como observamos, a população carente acaba ignorando normas e leis e responde como pode a seus problemas de acomodação na cidade. De alguma forma, a precariedade habitacional está sempre associada à presença dos seguintes indicadores: 1) questão fundiária não regularizada, posse ilegal, ocupação de terras inadequadas para edificação; 2) construçóes inadequadas, quer do ponto de vista estrutural, quer do conforto ambiental; 3) ausência de equipamentos e infraestrutura urbana; 4) congestionamento, superlotação de ambientes, falta de privacidade (Véras, 1992, p. 96). 
Aqui no morro nós viemos morar primeiro de aluguel na casa de um cunhado meu. Moramos de parede e meia um tempão, que a casinha dele só tinha quatro peças bem pequenas. Depois ficamos com o terreno porque ele morreu num acidente com a família. Com o tempo fomos arrumando ela. A casa a gente nunca termina de fazer, sempre falta coisa e não se tem dinheiro que chega pra arrumar. Mas eu penso que se dá pra morar dentro já tá bom (Alzira, Morro da Pedra).

Quando eu vim não tinha casa e tive que ir morar num porão, com pouca luz, com umidade, mas a gente tinha que ficar; se dividia aluguel com conhecidos e se morava tudo empilhado. Até a comida se fazia junto, no mesmo fogão. Depois se comprava um chão que dava pra ir pagando e se fazia uma morada de qualquer jeito que era pra escapar do aluguel, poder morar dentro e até pra receber os conhecidos que chegavam. Eu mesmo em Jaraguá morei em sete casas, mais ou menos, seis aqui no morro. (Seu Antônio, Morro da Pedra).

Nos domingos e feriados, nas horas de descanso, os trabalhadores constroem artesanalmente - com os parcos recursos disponíveis (conhecimento, ferramentas, materiais, mão-de-obra e poucas e parceladas economias) - uma parte da cidade, de forma que o assentamento residencial desta população em meio urbano, fundamental para a manutenção da oferta larga e barata de mão-de-obra, se faz à custa de seu próprio esforço.

Nesse aspecto, a periferia urbana, no curso desse processo desigual de urbanização, tem representado a alternativa possível à reprodução da maior parte da força de trabalho residente na cidade. Nesse contexto, a impossibilidade de adquirir os imóveis, próximos à área central e aos bairros adjacentes, seja a moradia, seja o terreno para edificá-la, em função dos seus elevados preços, tem determinado a expulsão desses moradores cada vez mais para a periferia (Silveira, 2003, p. 115). Esse deslocamento forçado, como vimos acima, acaba tendo, como destino "final", áreas sempre mais distantes - com precariedade ou inexistência de infraestrutura - e com baixa renda diferencial, entendida como o componente da renda fundiária que se baseia nas diferenças entre condiçóes físicas e localizações dos terrenos e nos diferenciais de investimentos sobre eles, ou no seu entorno, aplicados. Este componente soma-se à renda absoluta, que é, propriamente, a remuneração paga pela existência da propriedade privada (Bonduki; Rolnik, 1982, p. 147). 
Nesse sentido, a reprodução de consideráveis parcelas da força de trabalho, na cidade, tem-se efetivado, em geral, a partir da aquisiçáo de terrenos mais baratos nos dois morros ou pela invasão de áreas públicas sem as mínimas condiçóes de habitabilidade, principalmente por parte dos migrantes. Desssa forma, notadamente no Morro da Boa Vista, muitas casas são construídas dentro da mata, numa espécie de mimetismo ecológico arquitetônico.

Aqui o povo vai construindo assim mesmo, sem licença, sem prefeitura nem nada. Se chega aqui, derruba umas arvinha e faz em um dia, dois, um barraquinho de tábua velha. Tem muito disso aqui pra cima. Dá pra ver. Vem gente sem nada e vai construir desse jeito, né. O povo é pobre e não tem ajuda, então tem que se virá como pode. Um ajudando o outro aqui mesmo. Não tá certo isso, mas não tem outro jeito. Nem a prefeitura ajuda. Só atrapalha quando manda fiscal. Aí o povo tem que se esconder, sair pro mato e depois volta e continua a casa. Água se pega do morro, a casa tem rabicho de luz, esgoto manda pro mato. [...]. Vai lá ver o esgoto atrás da minha casa como é (Maria Rosa, Morro da Boa Vista).

Tal processo, geralmente, tem-se materializado na cidade, notadamente nas suas áreas periféricas, cujas principais características são, entre outras: a distribuição desordenada dos terrenos; a irregularidade do traçado viário; a debilidade da infra-estrutura e dos equipamentos urbanos; a improvisação das construçóes; a presença de mais de uma moradia por terreno e, em algumas vezes, de mais de uma família por casa, além da precariedade das residências, na maioria das vezes, submoradias ou casas coletivas (Jacobi, 2000, p. 13).

Contudo, e apesar disso, para os moradores do Morro da Boa Vista e do Morro da Pedra, suas casas autoconstruídas são claramente seu mais importante projeto de vida e consomem a maioria das suas energias e recursos por muitos anos. Através de suas casas, os moradores desenvolvem um discurso mediante o qual falam simultaneamente sobre a sociedade e sobre si mesmos. Para a maioria deles, o processo envolve não a compra de uma casa já pronta, mas todo o processo de construçáo, tanto material quanto simbólico, transformando-se no sonho em construçáo. Na periferia pobre, a casa é muito mais do que a casa, ela é o sonho de todos os moradores: a materialização de parte da venda da força de trabalho, dos esforços diários. Mais que madeiras ou parcelas de concreto e cimento armado, traz em si a 
história de luta dos indivíduos. Essas casas não podem ser compreendidas como um mero objeto, uma coisa entre as demais coisas: elas têm história (Santos, 2007, p. 218).

\section{Moradores entrevistados}

Alvir, de General Carneiro (PR), mora no Morro da Boa Vista desde 1986. Entrevista concedida em 19/08/2003.

Dona Alzira, de Cantagalo (PR), mora no Morro da Pedra desde 1990. Entrevista concedida em 05/09/2003.

Dona Maria Clara, de General Carneiro (PR), mora no Morro da Boa Vista desde 1986. Entrevista concedida em 12/08/2003.

Edenilson, de Cantagalo (PR), mora no Morro da Pedra desde 1995. Entrevista concedida em 05/09/2003.

José da Rosa, de Verê (PR), mora no Morro da Pedra desde 1990. Entrevista concedida em 27/08/2003.

Madalena de Souza, de Pompéia (SP), mora no Morro da Boa Vista desde 1986. Entrevista concedida em 31/07/2003.

Marcelino, de Dois Vizinhos (PR), mora no Morro da Pedra desde 1990. Entrevistas concedidas em 27/07/2003 e 04/09/2003.

Margarida, de Iporã (PR), mora no Morro da Boa Vista desde 1988. Entrevista concedida em 28/07/2003.

Maria Bernardete Rosa, nascida há 47 anos no Morro da Boa Vista. Entrevista concedida em 20/08/2003.

Maria Rosa, nascida há 38 anos no Morro da Boa Vista. Entrevista concedida em 20/08/2003.

Paulo, de General Carneiro (PR), mora no Morro da Boa Vista desde 1988. Entrevista concedida em 28/07/2003.

S. P., de Jaraguá do Sul, morou em vários lugares antes de ir para o Morro da Boa Vista, em 1989. Entrevista concedida em 21/08/2003.

Seu Antônio, de Cantagalo (PR), mora no Morro da Pedra desde 1994. Entrevista concedida em 05/09/2003. 
Seu Armando é de Luís Alves (SC), mora no Morro da Boa Vista desde 1984. Entrevista concedida em 08/08/2003.

V. B., de Quedas do Iguaçu (PR), mora no Morro da Boa Vista desde 1990. Entrevista concedida em 12/08/2003.

Veroni, de Dois Vizinhos (PR), mora no Morro da Pedra desde 1992. Entrevista concedida em $05 / 09 / 2003$.

\section{Referências}

BONDUKI, Nabil; ROLNIK, Raquel. Periferia da grande São Paulo: reprodução do espaço como expediente de reprodução da força do trabalho. In: MARICATO, Ermínia. (Org.). A produção capitalista da casa (e da cidade) no Brasil industrial. 2. ed. São Paulo: Alfa-Ômega, 1982.

CAIADO, Aurílio Sérgio. Metrópoles, cidades médias e pequenos municípios paulistas: estudo comparado da qualidade de vida e dinâmica sócio-espacial. In: PATARRA et al. Migração, condiçóes de vida e dinâmica urbana: São Paulo (1983-1993). Campinas: Unicamp/Instituto de Economia, 1997.

CALDEIRA, Teresa Pires. A politica dos outros: o cotidiano dos moradores da periferia e o que pensam do poder e dos poderosos. São Paulo: Brasiliense, 1984.

DAMIANI, Amélia. As contradiçóes do espaço: da lógica (formal) à (lógica) dialética. In: DAMIANI, Amélia; CARLOS, Ana Fani; SEABRA, Odette Carvalho. (Org.). O espaço no fim de século: a nova raridade. São Paulo: Contexto, 2001.

DURHAM, Eunice Ribeiro. A sociedade vista da periferia. Revista Brasileira de Ciências Sociais, São Paulo, v. I, n. 1, jun./1986.

GOMES, Paulo César. A condição urbana: ensaios de geopolítica da cidade. Rio de Janeiro: Bertrand Brasil, 2002.

JACOBI, Pedro. Cidade e meio ambiente. São Paulo: Annablume, 2000.

KOWARICK, Lúcio. A espoliação urbana. 2. ed. Rio de Janeiro: Paz e Terra, 1993. . Escritos urbanos. São Paulo: Editora 34, 2000.

MARICATO, Ermínia. Autoconstrução, a arquitetura possível. In: MARICATO, Ermínia. (Org.). A produção capitalista da casa (e da cidade) no Brasil industrial. 2. ed. São Paulo: Alfa-Ômega, 1982. 
Brasil, cidades: alternativas para a crise urbana. Petrópolis: Vozes, 2001.

PREFEITURA DE JAGUARÁ DO SUL. Plano estratégico municipal de assentamentos subnormais - Habitar Brasil-BID. Jaraguá do Sul: Mimeo, 2001.

SANTOS, Jânio. Alagados: um palco de estratégias da periferia. In: SERPA, Ângelo. (Org.). Cidade popular: trama de relaçôes sócio-espaciais. Salvador: EDUFBA, 2007.

SCARLATO, Francisco Capuano; PONTIN, Joel Arnaldo. O ambiente urbano. São Paulo: Atual, 1999.

SIEBERT, Cláudia. Blumenau fim de século: o (des)controle urbanístico e a exclusão sócio-espacial. In: THEIS, Ivo; TOMIO, Fabrício; MATTEDI, Marcos. (Org.). Novos olhares sobre Blumenau: contribuições críticas sobre seu desenvolvimento recente. Blumenau: Editora da FURB, 2000.

SILVEIRA, Rogério Leandro Lima da. Cidade, corporação e periferia urbana. Santa Cruz do Sul: EDUNISC, 2003.

VENETIER, P. Centre, périphérie et flux intra-urbains dans les grands villes d'Afrique noitre. Annales de Géographie, France, n. 547, mai-juin./1989.

VÉRAS, Maura Bicudo. Cortiços em São Paulo: velhas e novas formas da pobreza urbana e da segregação social. In: BÓGUS, Lúcia Maria; WANDERLEY, Luiz E. (Org.). A luta pela cidade em São Paulo. São Paulo: Cortez, 1992.

Resumo: Com a intensificação da industrialização de Jaraguá do Sul (SC), a partir dos anos 1960, aumentou o conjunto de oportunidades de trabalho, passando a cidade a representar o lugar da realização do sonho urbano da geração de empregos para trabalhadores rurais de várias regióes de Santa Catarina e de estados vizinhos, como o Paraná, que começaram a chegar à cidade, com maior intensidade, a partir dos anos 1980. Em Jaraguá do Sul, a maioria deles comprou um terreno que se localizava em locais - nesse caso, dois morros da cidade - sem a infraestrutura exigida pelos códigos municipais, o que pode ser facilmente visualizado em uma simples caminhada por suas ruas e vielas. No caso no Morro da Pedra, isso se deu em relaçáo a todos os terrenos quando os lotes começaram a ser vendidos nos anos 1980. Em relação ao Morro da Boa Vista, esta situação é mais flagrante na parte mais alta do morro, uma vez que na parte mais baixa há a facilidade de sua implementação, e quase sempre, os trabalhadores construíram suas casas sem a aprovação da planta na prefeitura, já que geralmente não podiam arcar com o custo que isso envolvia. Se morar é uma necessidade, é na desigualdade da localização e da qualidade habitacional que transparecem as diferenças entre as classes sociais. Neste sentido, as casas autoconstruídas são um dos expedientes de que se servem os trabalhadores pauperizados para solucionar seu problema de moradia, processo que os deixa presos a um projeto interminável, como bem mostram suas casas inacabadas. Além disso, essa situaçáo caracteriza-se pela utilizaçáo da água captada em fontes dos morros, em poços abertos sem cuidados higiênicos, no esgoto que corre a céu aberto em direção ao mato ou aos riachos. Assim, através de um conjunto de entrevistas, podemos analisar os diversos 
processos de ocupação do Morro da Boa Vista e do Morro da Pedra, bem como as formas de transformação do meio ambiente e os impactos ambientais e sociais causados neste.

Palavras-chave: Jaraguá do Sul, migração, morros, autoconstrução.

\title{
Two hills and their migrant residents in Jaraguá do Sul (SC): the water tank and the small well, the tiny trees and a little old wood shed, the sewage and the bushes
}

\begin{abstract}
With the increased industrialization of Jaragua do Sul (SC - Brazil) in the 1960s, the number of job opportunities increased throughout the city, which turned it into the place for the realization of the urban dream of jobs. Rural workers from various regions of Santa Catarina and neighboring states, such as Parana, began arriving in town, with greater intensity, from the year 1980. In Jaraguá do Sul, most of them bought land located in places without the required infrastructure by local codes (in that case, two hills in the city). Almost always, they built their houses without the City Hall approving their plan, since they generally could not afford the cost involved in such process. If living is a necessity, it is in the inequality in housing quality and location that the differences among social classes become apparent. In that sense, the self-built homes represent one of the attitudes taken by the poor employees to solve their housing problem, in a process that leaves them stuck to an endless project, as it is well shown by their unfinished houses. Moreover, this situation is characterized by the use of water collected from sources in the hills and from open wells, both without hygienic care, with sewage running in the open air into the woods or the streams. Thus, through a series of interviews, we analyze the various occupation processes of the hills Morro da Boa Vista and Morro da Pedra, as well as the ways of transforming their environment and the social and environmental impacts caused by those.
\end{abstract}

Keywords: Jaraguá do Sul, migration, hills, self-built homes.

Recebido em: 29/02/2012

Aprovado em: 02/08/2012 